\title{
Perturbation of the Hematopoietic Profile by Anabolic Androgenic Steroids
}

\author{
Jenny Erkander Mullen, ${ }^{1}$ Nina Gårevik, ${ }^{1}$ Jenny J. Schulze, ${ }^{1}$ Anders Rane, \\ Linda Björkhem Bergman, ${ }^{1,2}$ and Lena Ekström ${ }^{1}$ \\ ${ }^{1}$ Division of Clinical Pharmacology, Department of Laboratory Medicine, Karolinska Institutet, Karolinska University Hospital, \\ Huddinge, 14186 Stockholm, Sweden \\ ${ }^{2}$ Division of Clinical Microbiology, Department of Laboratory Medicine, Karolinska Institutet, Karolinska University Hospital, \\ Huddinge, 14186 Stockholm, Sweden
}

Correspondence should be addressed to Lena Ekström; lena.ekstrom@ki.se

Received 4 April 2014; Revised 11 September 2014; Accepted 14 September 2014; Published 22 September 2014

Academic Editor: Tullio Florio

Copyright (C) 2014 Jenny Erkander Mullen et al. This is an open access article distributed under the Creative Commons Attribution License, which permits unrestricted use, distribution, and reproduction in any medium, provided the original work is properly cited.

Objective. The aim of this study was to investigate the hematopoietic profile in AAS abusers, during or short after their last abuse and approximately six months later. Moreover, we studied if supraphysiological doses of testosterone influence the concentration of hemoglobin and erythropoietin in healthy volunteers. Design and Methods. Subjects $(N=31)$ were recruited through an antidoping hotline. The hematological profile was measured when the subjects entered the study and approximately 6 months later. Testosterone enanthate $(500 \mathrm{mg})$ was administered to healthy volunteers $(N=24)$. Gene expression was studied in human hek293 cells exposed to $1 \mu \mathrm{M}$ testosterone. Results. Decreased levels of hemoglobin, erythrocyte volume fraction, and erythrocyte counts were observed after 6 months without the use of AAS. Results in volunteers show that hemoglobin increased 3\% four and 15 days after testosterone administration, whereas EPO was significantly increased by $38 \%$ four days after dose. Agreeingly, in vitro study shows that testosterone induces the mRNA level of EPO with 65\% after 24-hour exposure. Conclusion. These results indicate that supraphysiological doses of testosterone may cause a perturbation in the hematopoietic profile. This is of interest in relation to the adverse cardiovascular effects observed in AAS abusers.

\section{Introduction}

The group of anabolic-androgenic steroids (AAS) includes testosterone and its analogue synthetic derivatives and chemical congeners. They are commonly abused by athletes and sportsmen to improve muscle mass and enhance exercise performance. AAS are the most frequently detected doping agents, testosterone being the predominant steroid (http://www.wada-ama.org). Notably, the abuse of these agents among nonprofessional athletes, as well as among people who want to enhance their physical appearance, is a growing public health problem and has become a major society concern [1-3].

The adverse effects of AAS on the cardiovascular system include adverse changes in cholesterol levels [4], endothelial dysfunction [5], and alterations of the structure of the heart, such as enlargement and thickening of the left ventricle which impairs its contraction and relaxation [6,7]. Several case reports suggest that AAS may induce thrombotic events such as myocardial infarction [8-13]. A possible mechanism contributing to thrombogenesis is an increase in hemoglobin $(\mathrm{Hb})$ associated with AAS use [14]. Such increases in hematocrit values have been associated with cardiovascular risks including atherosclerosis, coronary artery disease, and myocardial infarction [15-17].

Even though it is well known that testosterone increases hematocrit and hemoglobin during testosterone replacement therapy $[18,19]$ there are few studies investigating how supraphysiological doses of testosterone and other AAS such as those used in doping affect the hematological system. Alen found that power athletes using AAS have higher hematocrit, mean corpuscular hemoglobin concentration (MCHC), and 
erythrocyte sedimentation rate (ESR) compared to those not taking AAS [20]. Another small study showed that $67 \%$ of bodybuilders using AAS had elevated hematocrit levels [21].

Whether supraphysiological doses of testosterone induce erythropoietin (EPO) production in healthy men has not been studied before although it is known that androgens induce EPO concentrations in anemic patients [22, 23], in rodents [24, 25], and in hypogonadal men [26]. The aim of this study was to investigate the hematological profile in AAS abusers, during or short after their last abuse and approximately six months after discontinued use. Moreover, we studied if supraphysiological doses of testosterone influence the concentration of $\mathrm{Hb}$ and EPO in healthy volunteers.

\section{Subjects and Methods}

2.1. Study Group 1: AAS Abusers. Study group 1 consisted of clinical data from an earlier study in which thirty-one men between 18 and 57 years old had been recruited for the project between 1998 and 2002 [4]. A few were recruited by referral from colleagues working in emergency medicine, but most were asked to participate when contacting the antidoping hotline, a free telephone counseling service for individuals affected by or people concerned with abuse of anabolic androgenic steroids [1]. A genuine desire to give up the abuse of AAS was a prerequisite to be included. Participation was commenced after informed consent, and no economical remuneration was given to participants. The project was approved by the Ethics Committee of the Karolinska Institutet, Stockholm, Sweden. In this study blood samples were collected at different time points and a series of hematological parameters were monitored. These hematological parameters including $\mathrm{Hb}$, erythrocyte counts, erythrocyte volume fraction (EVF), thrombocyte count, Hb mass, mean corpuscular volume (MCV), and mean corpuscular hemoglobin concentration (MCHC) were analyzed at their first visit and compared to values six months later. At each visit the participants met with a research nurse who could answer questions and check their social and psychological condition. If necessary, individuals were referred to qualified medical assessment and treatment at the psychiatric or endocrine departments of the hospital.

2.2. Study Population 2: Healthy Volunteers. This group included 24 male volunteers aged $27-43$ years (mean $33.8 \pm$ 4.7). All participants underwent a medical examination including laboratory tests before enrolment. All participants had negative screening tests for illegal drugs, AAS, HIV, and hepatitis $\mathrm{B}$ or $\mathrm{C}$ virus and were not taking any therapeutic drugs. The participants were given a $500 \mathrm{mg}$ intramuscular dose of testosterone enanthate (Testoviron, Depot). Blood samples were collected prior to (day 0 ) and four and fourteen days after testosterone administration for analyses. Blood samples were collected between $07.00 \mathrm{~h}$ and $09.00 \mathrm{~h}$ after an overnight fast. The study was approved by the local ethics committee and was performed in accordance with the Helsinki declaration. Written informed consent was obtained from all study participants before they entered the study.
2.3. Hematological and Hormone Measurements. Hb, erythrocyte counts, erythrocyte volume fraction (EVF), thrombocyte count, $\mathrm{Hb}$ mass, mean corpuscular volume (MCV), and mean corpuscular hemoglobin concentration (MCHC) in study group 1 (AAS abusers) were analyzed at the Department of Clinical Chemistry, Karolinska University Hospital, using standard clinical routine methods. The samples from study group 2 (healthy volunteers) were analyzed for total serum testosterone and EPO concentration also using routine immunochemical methods. $\mathrm{Hb}$ was analyzed using HemoCue analyzing system.

2.4. Cell Experiments. Hek293 cells were cultured in minimum essential medium, $10 \%$ fetal bovine serum, and $1 \mathrm{mM}$ sodium pyruvate. All cell culture media and their ingredients were obtained from Life Technology. Cells were plated in 24-well plates and grown overnight. Testosterone enanthate (Sigma Aldrich) dissolved in ethanol was added to the cells $(1 \mu \mathrm{M})$ and grown overnight $(16 \mathrm{~h})$. The nontreated controls were incubated with vehicle only. Each treatment was performed in six independent experiments. The cells were harvested with $200 \mu \mathrm{L}$ trizol (Invitrogen, UK) and total RNA was extracted according to manufacturer's instructions. The RNA $(0.3 \mu \mathrm{g})$ was reverse transcribed into cDNA with hexamer primer using High Capacity cDNA Reverse Transcriptase kit (Applied Biosystems) according to the manufacturer's protocol and diluted 10 times.

2.5. Real Time PCR. The mRNA levels of EPO in testosterone treated Hek293 cells were determined by real time PCR. GAPDH (\# 4310884E Applied Biosystems) was chosen as endogenous housekeeping control gene. Quantitative real time PCR was performed using the 7500 Fast (Applied Biosystems). Reaction mixtures contained 2xTaqman reaction mix (Applied Biosystems), $1 \mu \mathrm{L}$ of gene specific expression assay (Hs01071097_ml, Applied Biosystems, Foster City, $\mathrm{CA}$ ), and $2 \mu \mathrm{L}$ cDNA template in a total volume of $15 \mu \mathrm{L}$. Thermal cycling conditions included activation at $95^{\circ} \mathrm{C}$ (10 min) followed by 45 cycles each of denaturation at $95^{\circ} \mathrm{C}(15 \mathrm{sec})$ and annealing/elongation at $60^{\circ} \mathrm{C}(1 \mathrm{~min})$. Each reaction was performed in triplicate and no-template controls were included in each experiment. The untreated samples were employed as calibrators and the delta delta CT-formula was used as previously described [27]. The gene expression was quantified as the yield of the target gene relative to that of GAPDH gene.

2.6. Data Analysis. The concentrations of hematological parameters in AAS abusers and the concentration of EPO prior to and after testosterone exposure were compared using paired $t$-test. EPO and $\mathrm{Hb}$ in healthy volunteers prior and after the administration of testosterone were compared using Friedman test followed by Dunns comparison test. The mean values are presented as mean $\pm \mathrm{SD}$. The correlation analysis between EPO and total testosterone was performed using Spearman's rank test. The EPO mRNA level in Hek293 cells, prior to and after testosterone exposure, was compared using Mann-Whitney test. All statistical analysis was performed 
TABLE 1: Characteristic data of study group 1 at the time of inclusion (visit 1 ) and after 6 months cessation of AAS.

\begin{tabular}{lc}
\hline Mean age (range) & $26.4 \mathrm{y}(18-57)$ \\
AAS duration (range) & $5.2 \mathrm{y}(0.5-17)$ \\
Last AAS intake (range) & 84 days ago (0-365) \\
$\%$ Tested positive for & $61 \%$ \\
$\quad$ Nandrolone & $54 \%$ \\
Testosterone & $35 \%$ \\
Stanozolol & \\
Total Testosterone concentration & $19.1 \mathrm{mmol} / \mathrm{L}(0.7-137)$ \\
Mean (range) visit 1 & $14.2 \mathrm{mmol} / \mathrm{L}(5.6-49)$ \\
Mean (range) visit 2 & $63 \%$ \\
$\%$ Hypogonadal $<12 \mathrm{mmol} / \mathrm{L}$ & $43 \%$ \\
Visit 1 & \\
Visit 2 &
\end{tabular}

using InStat software version 5.01 (GraphPad, San Diego, CA).

\section{Results}

3.1. Steroid Profile in AAS Abusers. Thirty-one of the 56 AAS subjects that tested positive for nandrolone, testosterone, and/or stanozolon at the first visit, did not relapse into AAS abuse, and returned to a 6-month follow-up were included. The mean age was 26.4 (range 18-57), the mean time on AAS abuse was 5.2 years (range $0.5-17$ ), and the mean time since last reported AAS intake was 84 days (range 0-365). Fifty-four percent tested positive for testosterone, $61 \%$ for nandrolone, and 35\% for stanozolol.

Sixty-three percent of the included AAS abusers were hypogonadal ( $<12 \mathrm{mmol} / \mathrm{L}$ total testosterone) as defined by [28] when they enrolled in the study, whereas at the 6-month follow-up visit $43 \%$ were still identified as hypogonadal. Four of the included subjects displayed extremely high circulatory concentration of total testosterone $(>50 \mathrm{mmol} / \mathrm{L})$. Three of these individuals reported a use of AAS within the last 3 weeks. All data about the AAS abusers study population have been summarized in Table 1 .

3.2. Hematological Profiles in AAS Abusers. Hb was significantly higher at the first visit (mean $162 \pm 11 \mathrm{~g} / \mathrm{L}$ ) as compared to after 6 months without AAS (mean $155 \pm 9.5 \mathrm{~g} / \mathrm{L}$ ), $P=0.0005$. Seventy-seven percent of the participants showed lower $\mathrm{Hb}$ at the second visit (Figure 1(a)).

Erythrocyte count was significantly higher at the first visit (mean $5.5 \pm 0.41 \times 10^{12} / \mathrm{L}$ ) as compared to the 6 -month follow-up (mean $5.2 \pm 0.49$ ), $P=0.0008$ (Figure 1(b)). Similarly $87 \%$ of the participants had decreased their erythrocyte count at the second visit.

EVF was significantly higher at the first visit (mean $47.2 \pm$ $2.9 \%)$ than after 6 months without AAS $(45.0 \pm 2.8), P=$ 0.0008 (Figure 1(c)). Sixty-five \% of the participants exhibit lower levels at visit 2 as compared to visit 1.
The level of thrombycotes, $\mathrm{Hb}$ mass, $\mathrm{MCV}$, and MCHC did not significantly differ between the two visits (Figures $1(\mathrm{~d})-1(\mathrm{~g}))$.

3.3. Hematological Profiles in Healthy Volunteers. The concentration of EPO was significantly $38 \%$ higher four days after the administration of $500 \mathrm{mg}$ testosterone enanthate (mean $11.55 \pm 3.41 \mathrm{E} / \mathrm{L}$ ) as compared to day 0 (mean $8.15 \pm 2.66$ ), $P=$ 0.03 . An increase was observed in $85 \%$ of the participants. The EPO concentrations were back to baseline values on day 15 (mean $10.58 \pm 4.30$ ) (Figure 2(a)).

There was a minor $3 \%$ increase in the $\mathrm{Hb}$ concentration four days after the testosterone injection, which remained 15 days after testosterone dose $(P=0.04)$ (Figure 2(b)).

There was no correlation between the EPO and testosterone concentrations on day 0 whereas on day 4 a significant correlation between the increase in EPO and increase in testosterone was observed ( $r=0.64, P=0.01$ ) (Figure 3 ).

3.4. EPO Gene Expression in Testosterone Exposed Hek-293 Cells. Hek293 cells were exposed to testosterone enanthate $(1 \mu \mathrm{M})$ for $16 \mathrm{~h}$ and the mRNA levels of EPOwere determined by real time PCR. Testosterone enanthate induced EPO mRNA levels 1.8-fold compared to the vehicle treated controls $(P=0.01)$, Figure 4 . These data indicate that testosterone modifies the transcriptional activity of EPO in Hek293 cells.

\section{Discussion}

It is generally known that AAS abuse leads to elevated levels of hematocrit and $\mathrm{Hb}$ as has been demonstrated in bodybuilders $[20,21,29]$. Here we show for the first time that cessation of AAS abuse results in a decrease in $\mathrm{Hb}, \mathrm{EVF}$, and erythrocytes count. It is generally known that testosterone affects the hematological profile even though limited scientific data exists supporting this in young healthy men who are most likely to use AAS for doping purpose. Several studies have shown that therapeutic use of testosterone stimulates erythropoiesis, particularly when using testosterone ester injections. In fact erythrocytosis is the most frequent doselimiting adverse event of testosterone replacement therapy [30]. The molecular explanation behind the erythropoietin stimulatory effect of testosterone is not known, but several hypotheses propose that androgens exert a direct effect on the bone marrow (extensively reviewed by Shahani et al. [31]). Bachman et al. suggested that suppression of hepcidin may be a putative link [32].

In addition, our results indicate that supraphysiological doses of testosterone increase the production of EPO in healthy volunteers. Our results are in agreement with an animal study [25] and a small human study [22] showing that testosterone induce EPO production. However, some studies failed to find an increase in EPO after administration of testosterone in hypogonadal men $[33,34]$. Our results support the notion that testosterone induces EPO, at least in healthy men. Analysis of the correlation between the increase in total testosterone and EPO on day four further supports the theory that the increase in EPO is testosterone dependent, 


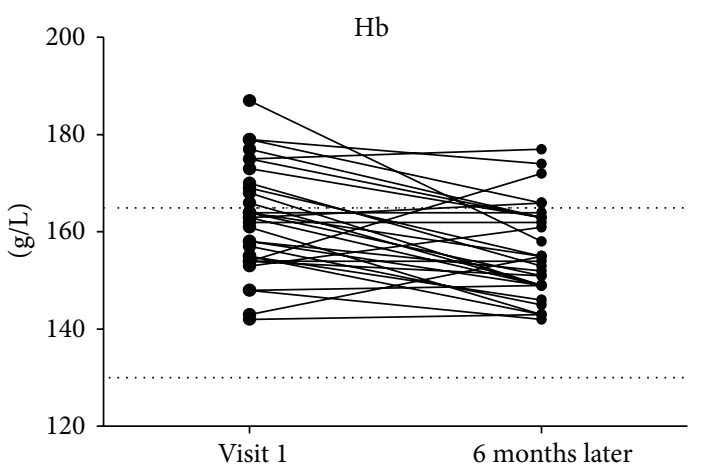

(a)

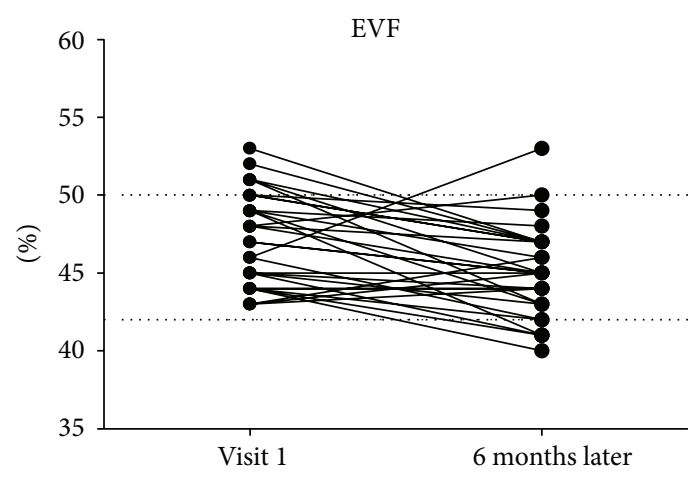

(c)

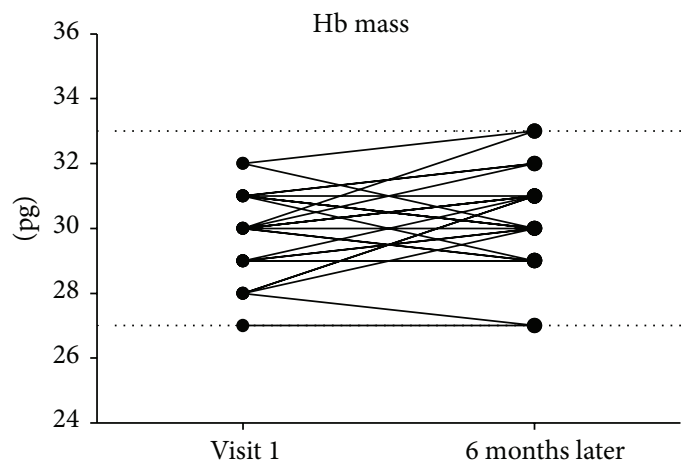

(e)

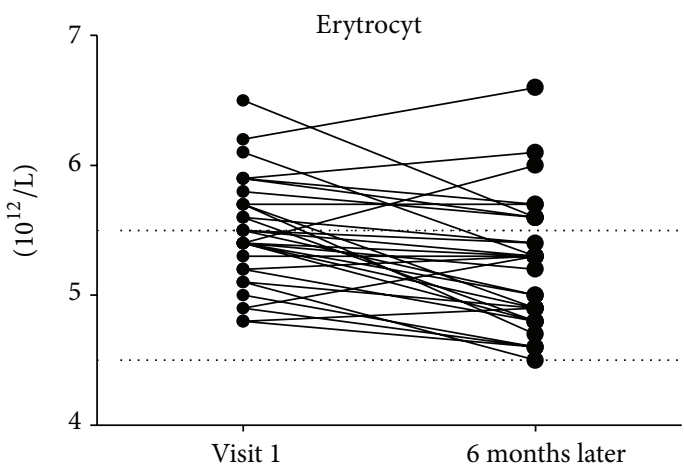

(b)

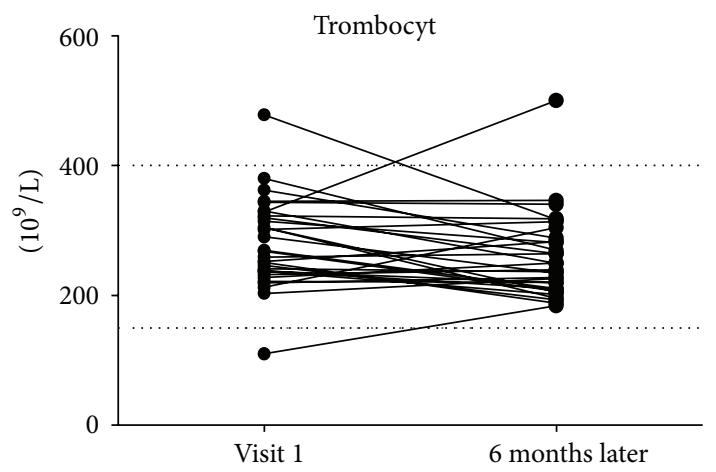

(d)

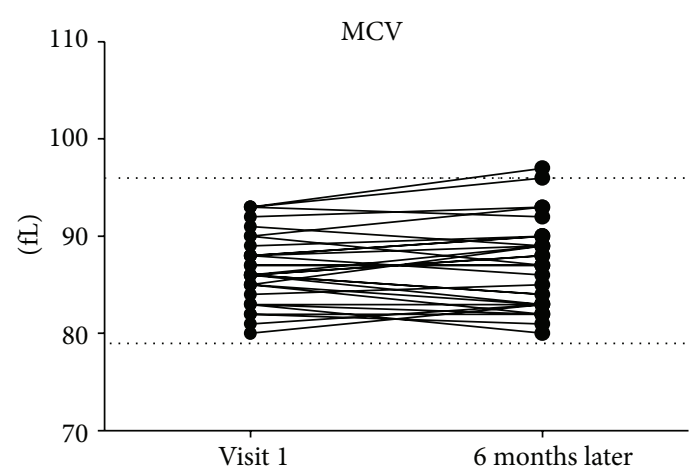

(f)

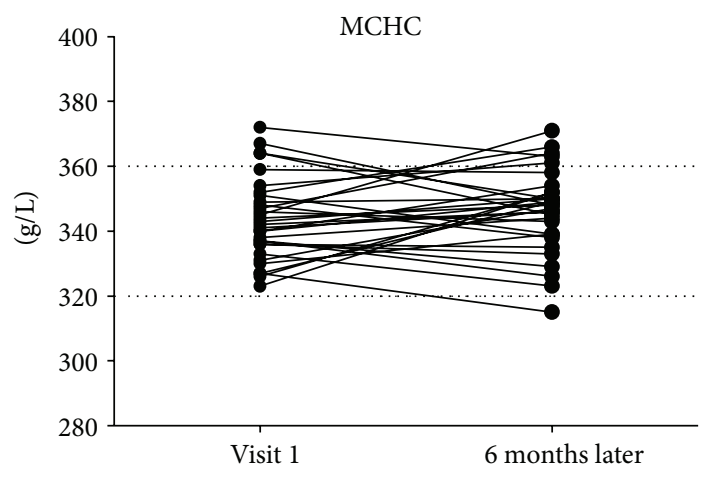

(g)

FIGURE 1: Hematologic profile in the AAS abusers when they entered the study (visit 1) and approximately 6 months after the cessation of the abuse. The dotted line marks the minimum and maximum normal values for men between 20 and 50 years. There was a significant decrease in (a) Hb, (b) erythrocyte count, and (c) EVF, whereas there were no significant differences in (d) thrombocyte, (e) Hb mass, (f) MCV, or (g) $\mathrm{MCHC}$. 


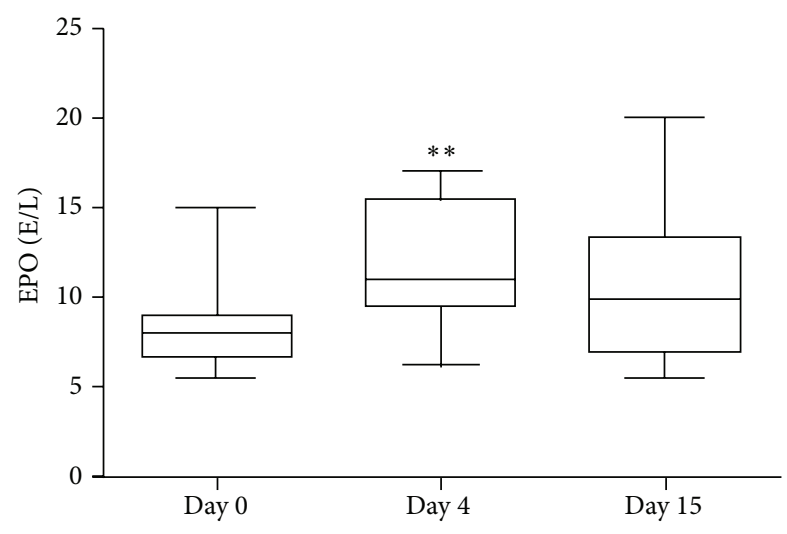

(a)

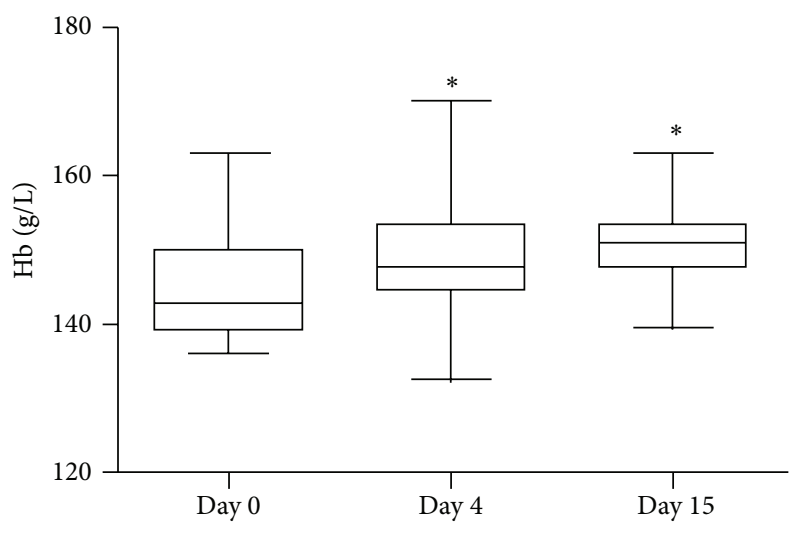

(b)

FIGURE 2: The concentration of (a) EPO and (b) Hb in healthy volunteers prior to the injection of $500 \mathrm{mg}$ testosterone enanthate (day 0 ) and four and fifteen days after. A significant increase in EPO was observed on day 4 but it was back to baseline on day 15 . Hb was significantly elevated on day 4 and day 15 .

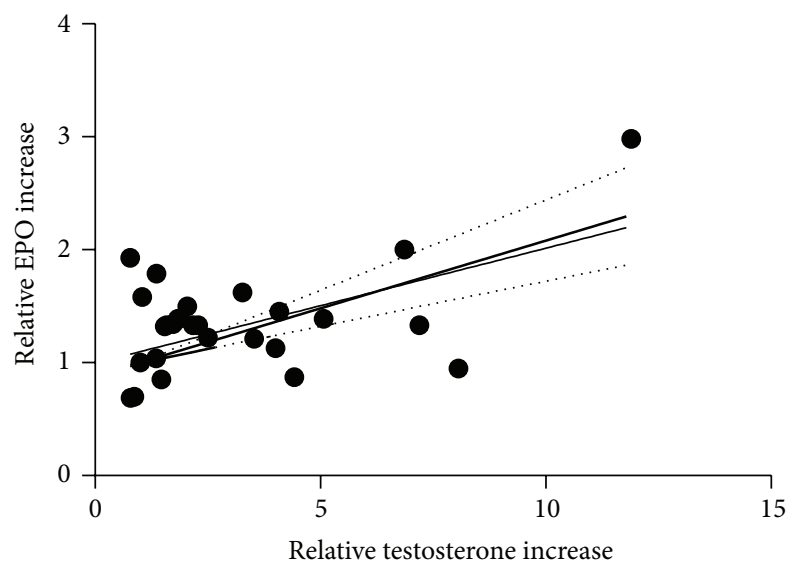

FIGURE 3: The relative fold increase of serum levels of testosterone (T) compared to relative increase in EPO between day 0 and day 4 . A linear regression has been made to fit the data. The dotted line marks the $95 \%$ confidence interval of the line.

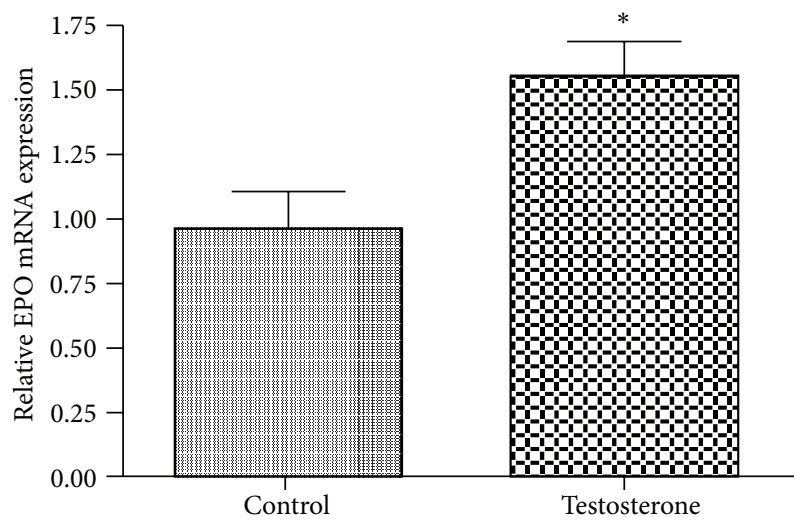

FIGURE 4: The mRNA levels in Hek293 cells exposed to testosterone $(1 \mu \mathrm{M})$ for $24 \mathrm{~h}$. There was a significant increase in EPO mRNA expression as compared to control. at least partly. This assumption received further support by our in vitro results showing that a supraphysiological dose of testosterone increases the gene expression of EPO with 65\% in Hek23 cells. The testosterone concentration used in our in vitro experiments $(1 \mu \mathrm{M})$ is within the range of the serum levels achieved after administration of $500 \mathrm{mg}$ testosterone enantahte to healthy volunteers [35]. In agreement with our finding, a recent study showed that testosterone induces the mRNA expression of EPO in rats [36]. It has also been shown that androgens may increase the expression of the EPO receptor [37] indicating a further biological effect of androgens.

We show that the EPO induction in healthy volunteers was accompanied by an increase in Hb. In contrast to EPO, $\mathrm{Hb}$ was still elevated 15 days after dose which probably is due to the long life span of the erythrocytes [38]. It is possible that $\mathrm{EPO}$ and $\mathrm{Hb}$ may be even more elevated after repeated use of testosterone. Even though the $\mathrm{Hb}$ increase was minor (intersubject variation between $-4 \%$ and $+14 \%$ ) it may contribute to performance enhancing effects in the athletes.

The Athlete Biological Passport, introduced by WADA, is a new means of doping testing that aims to monitor consecutive samples from the same individual. This passport comprises of three modules, the steroid, the hematocrit, and the endocrine profile [39]. Our results show that the intake of testosterone affects not only the steroid profile but also the hematocrit profile. Hence an increase in $\mathrm{Hb}$ and EVF is cause for suspicion of AAS use, just as is the case in blood doping. This needs to be taken into account when expert panels are judging the profiles in future test programs.

Even though at least six months had passed since the AAS abusers took their last dose, several of the subjects were still displaying low levels of circulatory total testosterone at their follow-up visit. It is known that the time adapting to a normal endocrine level may take years or even be irreversible in some cases [40-43]. Our previous studies involving the same AAS abusers have shown that nandrolone has a long standing effects on LH and FSH [4]. The concentrations of 
total testosterone in four of the abusers were above $50 \mathrm{nmol} / \mathrm{L}$ at the first visit and as high as $137 \mathrm{nmol} / \mathrm{L}$ for one subject. Such high circulatory concentrations of testosterone have been observed before in AAS abusers [44].

No changes in thrombocytes count were seen after discontinued AAS use. Ferenhick found that weight lifters using AAS showed a significant trend towards increased platelet counts compared to nonusers [45]. Indirectly, testosterone may exert prothrombotic effects through its aromatization to estradiol, in contrast to nandrolone. When including only individuals that were positive for testosterone doping, that is, with a $\mathrm{T} / \mathrm{E}$ ratio above 4 , a significant $15 \%$ decrease in thrombocytes count was found (data not shown).

Despite an increasing knowledge that AAS use increases the risk of cardiovascular diseases there are, as expected, no prospective interventional studies on the long term cardiovascular effects of AAS use to date [14]. It is difficult to study the effects of AAS in vivo. For ethical and medical reasons only single doses of AAS may be studied in healthy volunteers. The medical examination of AAS abusers may give some information about the effects of AAS but one drawback using AAS users is that in some cases the AAS are coused with other drugs, such as clenbuterol, growth hormone, and aromatase inhibitors. The population used herein must be considered rather unique since the coabuse of narcotics was rare at the time of inclusion. Only three subjects were withdrawn from the study due to positive narcotics tests. Another drawback with this study is that the time since their last AAS use differs markedly, making it impossible to draw any conclusion on the time frame for normalization of the hematocrit.

In conclusion, we have shown that a cessation of AAS use leads to significant decrease in $\mathrm{Hb}$, hematocrit, and erythrocyte counts, notably leading to a normalization of these values. In healthy men, administration of supraphysiological dose of testosterone increased $\mathrm{Hb}$ and the concentration of EPO. It is possible that stimulation of erythropoiesis together with perturbation in the cholesterol profile and endothelial health may all contribute to an increased risk of cardiovascular events in AAS users.

\section{Conflict of Interests}

The authors declare that there is no conflict of interests regarding the publication of this paper.

\section{Acknowledgment}

This work was supported by grants from World Anti-Doping Agency (WADA).

\section{References}

[1] A.-C. Eklöf, A.-M. Thurelius, M. Garle, A. Rane, and F. Sjöqvist, "The anti-doping hot-line, a means to capture the abuse of doping agents in the Swedish society and a new service function in clinical pharmacology," European Journal of Clinical Pharmacology, vol. 59, no. 8-9, pp. 571-577, 2003.
[2] G. Kanayama, K. J. Brower, R. I. Wood, J. I. Hudson, and H. G. Pope Jr., "Anabolic-androgenic steroid dependence: an emerging disorder," Addiction, vol. 104, no. 12, pp. 1966-1978, 2009.

[3] F. Sjöqvist, M. Garle, and A. Rane, "Use of doping agents, particularly anabolic steroids, in sports and society," The Lancet, vol. 371, no. 9627, pp. 1872-1882, 2008.

[4] N. Gårevik, E. Strahm, M. Garle et al., "Long term perturbation of endocrine parameters and cholesterol metabolism after discontinued abuse of anabolic androgenic steroids," The Journal of Steroid Biochemistry and Molecular Biology, vol. 127, no. 3-5, pp. 295-300, 2011.

[5] C. Skogastierna, M. Hotzen, A. Rane, and L. Ekström, "A supraphysiological dose of testosterone induces nitric oxide production and oxidative stress," European Journal of Preventive Cardiology, vol. 21, no. 8, pp. 1049-1054, 2013.

[6] G. McKillop, I. C. Todd, and D. Ballantyne, "Increased left ventricular mass in a bodybuilder using anabolic steroids," British Journal of Sports Medicine, vol. 20, no. 4, pp. 151-152, 1986.

[7] S. E. Campbell, A. Farb, and K. T. Weber, "Pathologic remodeling of the myocardium in a weightlifter taking anabolic steroids. Case report," Blood Pressure, vol. 2, no. 3, pp. 213-216, 1993.

[8] R. A. McNutt, G. S. Ferenchick, P. C. Kirlin, and N. J. Hamlin, "Acute myocardial infarction in a 22-year-old world class weight lifter using anabolic steroids," The American Journal of Cardiology, vol. 62, no. 1, p. 164, 1988.

[9] M. J. Huie, "An acute myocardial infarction occurring in an anabolic steroid user," Medicine and Science in Sports and Exercise, vol. 26, no. 4, pp. 408-413, 1994.

[10] R. G. Alvarado, J. Y. Liu, and R. M. Zwolak, "Danazol and limbthreatening arterial thrombosis: two case reports," Journal of Vascular Surgery, vol. 34, no. 6, pp. 1123-1126, 2001.

[11] K. McCarthy, A. T. M. Tang, M. J. R. Dalrymple-Hay, and M. P. Haw, "Ventricular thrombosis and systemic embolism in bodybuilders: etiology and management," Annals of Thoracic Surgery, vol. 70, no. 2, pp. 658-660, 2000.

[12] T. J. Montine and J. T. Gaede, "Massive pulmonary embolus and anabolic steroid abuse," The Journal of the American Medical Association, vol. 267, no. 17, pp. 2328-2329, 1992.

[13] M. A. Sahraian, M. Mottamedi, A. R. Azimi, and B. Moghimi, "Androgen-induced cerebral venous sinus thrombosis in a young body builder: case report," BMC Neurology, vol. 4, no. 1, article 22, 2004.

[14] P. Vanberg and D. Atar, "Androgenic anabolic steroid abuse and the cardiovascular system," Handbook of Experimental Pharmacology, vol. 195, pp. 411-457, 2010.

[15] D. R. Gagnon, T.-J. Zhang, F. N. Brand, and W. B. Kannel, "Hematocrit and the risk of cardiovascular disease-the framingham study: a 34-year follow-up," American Heart Journal, vol. 127, no. 3, pp. 674-682, 1994.

[16] B. D. Spiess, C. Ley, S. C. Body et al., "Hematocrit value on intensive care unit entry influences the frequency of Q-wave myocardial infarction after coronary artery bypass grafting," The Journal of Thoracic and Cardiovascular Surgery, vol. 116, no. 3, pp. 460-467, 1998.

[17] A. Goubali, G. Voukiklaris, S. Kritsikis, F. Viliotou, and D. Stamatis, "Relation of hematocrit values to coronary heart disease, arterial hypertension, and respiratory impairment in occupational and population groups of the Athens area," Angiology, vol. 46, no. 8, pp. 719-725, 1995. 
[18] S. Bhasin, L. Woodhouse, R. Casaburi et al., "Older men are as responsive as young men to the anabolic effects of graded doses of testosterone on the skeletal muscle," Journal of Clinical Endocrinology and Metabolism, vol. 90, no. 2, pp. 678-688, 2005.

[19] S. Bhasin, L. Woodhouse, R. Casaburi et al., "Testosterone doseresponse relationships in healthy young men," American Journal of Physiology-Endocrinology and Metabolism, vol. 281, no. 6, pp. E1172-E1181, 2001.

[20] M. Alén, "Androgenic steroid effects on liver and red cells," British Journal of Sports Medicine, vol. 19, no. 1, pp. 15-20, 1985.

[21] R. D. Dickerman, R. Pertusi, N. Y. Zachariah, and F. Schaller, "Androgen-induced erythrocytosis," American Journal of Hematology, vol. 59, no. 3, pp. 263-264, 1998.

[22] N. Rishpon-Meyerstein, T. Kilbridge, J. Simone, and W. Fried, "The effect of testosterone on erythropoietin levels in anemic patients," Blood, vol. 31, no. 4, pp. 453-460, 1968.

[23] R. Alexanian, "Erythropoietin and erythropoiesis in anemic man following androgens," Blood, vol. 33, no. 4, pp. 564-572, 1969.

[24] D. G. Nathan and F. H. Gardner, "Effects of large doses of androgen on rodent erythropoiesis and body composition.," Blood, vol. 26, no. 4, pp. 411-420, 1965.

[25] L. A. Malgor, M. Valssecia, E. Verges, and E. E. de Markowsky, "Blockade of the in vitro effects of testosterone and erythropoietin on CFU-E and BFU-E proliferation by pretreatment of the donor rats with cyproterone and flutamide," Acta Physiologica Pharmacologica et Therapeutica Latinoamericana, vol. 48, no. 2, pp. 99-105, 1998.

[26] A. D. Coviello, B. Kaplan, K. M. Lakshman, T. Chen, A. B. Singh, and S. Bhasin, "Effects of graded doses of testosterone on erythropoiesis in healthy young and older men," Journal of Clinical Endocrinology and Metabolism, vol. 93, no. 3, pp. 914919, 2008.

[27] K. J. Livak and T. D. Schmittgen, "Analysis of relative gene expression data using real-time quantitative PCR and the $2^{-\triangle \triangle C_{T}}$ method," Methods, vol. 25, no. 4, pp. 402-408, 2001.

[28] S. Arver and M. Lehtihet, "Current guidelines for the diagnosis of testosterone deficiency," Frontiers of Hormone Research, vol. 37, pp. 5-20, 2009.

[29] R. D. Dickerman, R. Pertusi, J. Miller, and N. Y. Zachariah, "Androgen-induced erythrocytosis: is it erythropoietin?" The American Journal of Hematology, vol. 61, no. 2, pp. 154-155, 1999.

[30] S. Bhasin, G. R. Cunningham, F. J. Hayes et al., “Testosterone therapy in adult men with androgen deficiency syndromes: an endocrine society clinical practice guideline," Journal of Clinical Endocrinology and Metabolism, vol. 91, no. 6, pp. 1995-2010, 2006.

[31] S. Shahani, M. Braga-Basaria, M. Maggio, and S. Basaria, "Androgens and erythropoiesis: past and present," Journal of Endocrinological Investigation, vol. 32, no. 8, pp. 704-716, 2009.

[32] E. Bachman, R. Feng, T. Travison et al., “Testosterone suppresses hepcidin in men: a potential mechanism for testosteroneinduced erythrocytosis," Journal of Clinical Endocrinology and Metabolism, vol. 95, no. 10, pp. 4743-4747, 2010.

[33] F. F. Ip, I. Di Pierro, R. Brown, I. Cunningham, D. J. Handelsman, and P. Y. Liu, "Trough serum testosterone predicts the development of polycythemia in hypogonadal men treated for up to 21 years with subcutaneous testosterone pellets," European Journal of Endocrinology, vol. 162, no. 2, pp. 385-390, 2010.

[34] M. Maggio, P. J. Snyder, G. P. Ceda et al., "Is the haematopoietic effect of testosterone mediated by erythropoietin? The results of a clinical trial in older men," Andrology, vol. 1, no. 1, pp. 24-28, 2013.

[35] L. Ekström, J. J. Schulze, C. Guillemette, A. Belanger, and A. Rane, "Bioavailability of testosterone enanthate dependent on genetic variation in the phosphodiesterase $7 \mathrm{~B}$ but not on the uridine $5^{\prime}$-diphospho- glucuronosyltransferase (UGT2B17) gene," Pharmacogenetics and Genomics, vol. 21, no. 6, pp. 325332, 2011.

[36] W. Guo, E. Bachman, M. Li et al., “Testosterone administration inhibits hepcidin transcription and is associated with increased iron incorporation into red blood cells," Aging Cell, vol. 12, no. 2, pp. 280-291, 2013.

[37] V. Pelekanou, G. Notas, E. Sanidas, A. Tsapis, E. Castanas, and M. Kampa, "Testosterone membrane-initiated action in breast cancer cells: interaction with the androgen signaling pathway and EPOR," Molecular Oncology, vol. 4, no. 2, pp. 135-149, 2010.

[38] N. T. Shahidi, “Androgens and erythropoiesis," The New England Journal of Medicine, vol. 289, no. 2, pp. 72-80, 1973.

[39] P.-E. Sottas and A. Vernec, "Current implementation and future of the athlete biological passport," Bioanalysis, vol. 4, no. 13, pp. 1645-1652, 2012.

[40] A. Clerico, M. Ferdeghini, C. Palombo et al., "Effect of anabolic treatment on the serum levels of gonadotropins, testosterone, prolactin, thyroid hormones and myoglobin of male athletes under physical training," The Journal of Nuclear Medicine and Allied Sciences, vol. 25, no. 3, pp. 79-88, 1981.

[41] K. Boregowda, L. Joels, J. W. Stephens, and D. E. Price, "Persistent primary hypogonadism associated with anabolic steroid abuse," Fertility and Sterility, vol. 96, no. 1, pp. e7-e8, 2011.

[42] J. P. Jarow and L. I. Lipshultz, "Anabolic steroid-induced hypogonadotropic hypogonadism," American Journal of Sports Medicine, vol. 18, no. 4, pp. 429-431, 1990.

[43] I. Pirola, C. Cappelli, A. Delbarba et al., "Anabolic steroids purchased on the Internet as a cause of prolonged hypogonadotropic hypogonadism," Fertility and Sterility, vol. 94, no. 6, pp. 2331-e1, 2010.

[44] G. Kanayama, J. Kean, J. I. Hudson, and H. G. Pope, "Cognitive deficits in long-term anabolic-androgenic steroid users," Drug and Alcohol Dependence, vol. 130, no. 1-3, pp. 208-214, 2013.

[45] G. S. Ferenchick, S. Hirokawa, E. F. Mammen, and K. A. Schwartz, "Anabolic-androgenic steroid abuse in weight lifters: evidence for activation of the hemostatic system," The American Journal of Hematology, vol. 49, no. 4, pp. 282-288, 1995. 


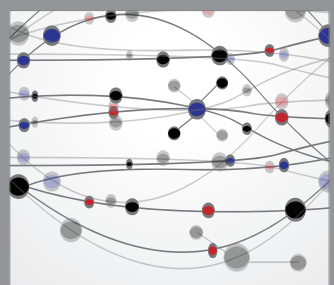

The Scientific World Journal
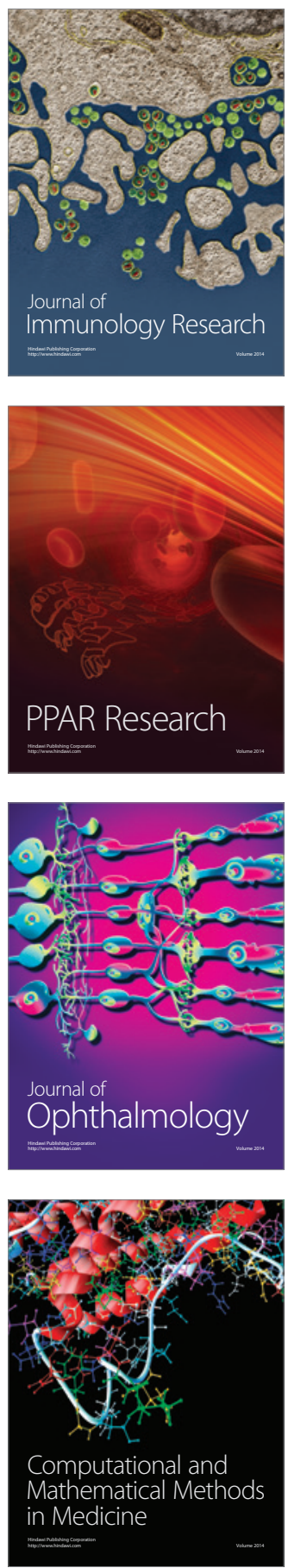

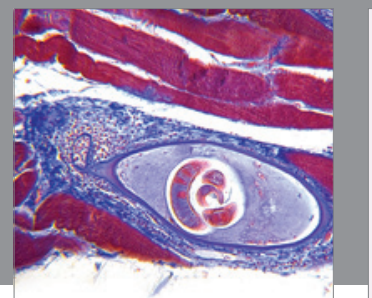

Gastroenterology

Research and Practice
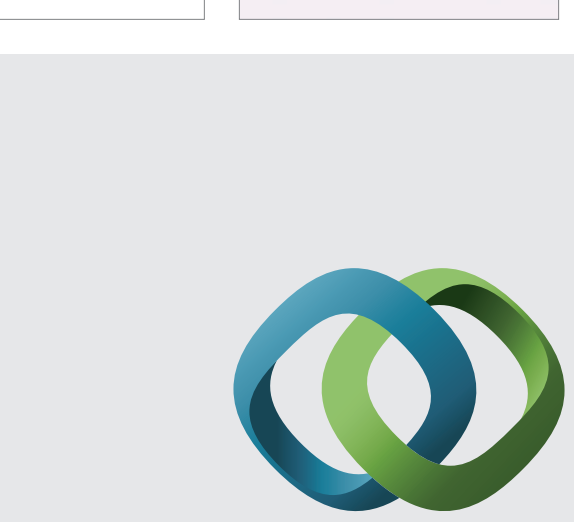

\section{Hindawi}

Submit your manuscripts at

http://www.hindawi.com
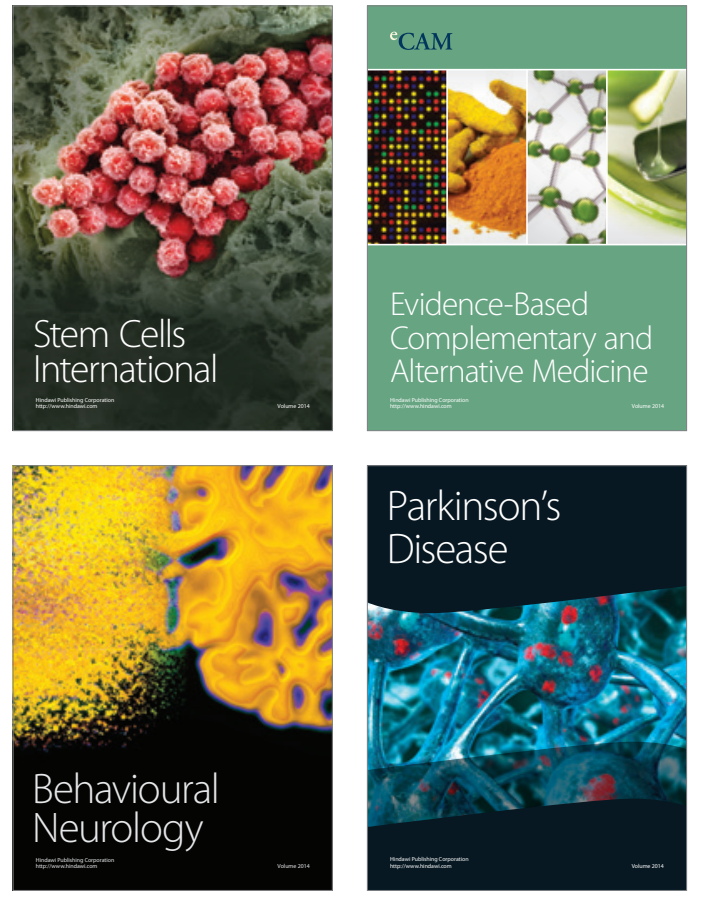
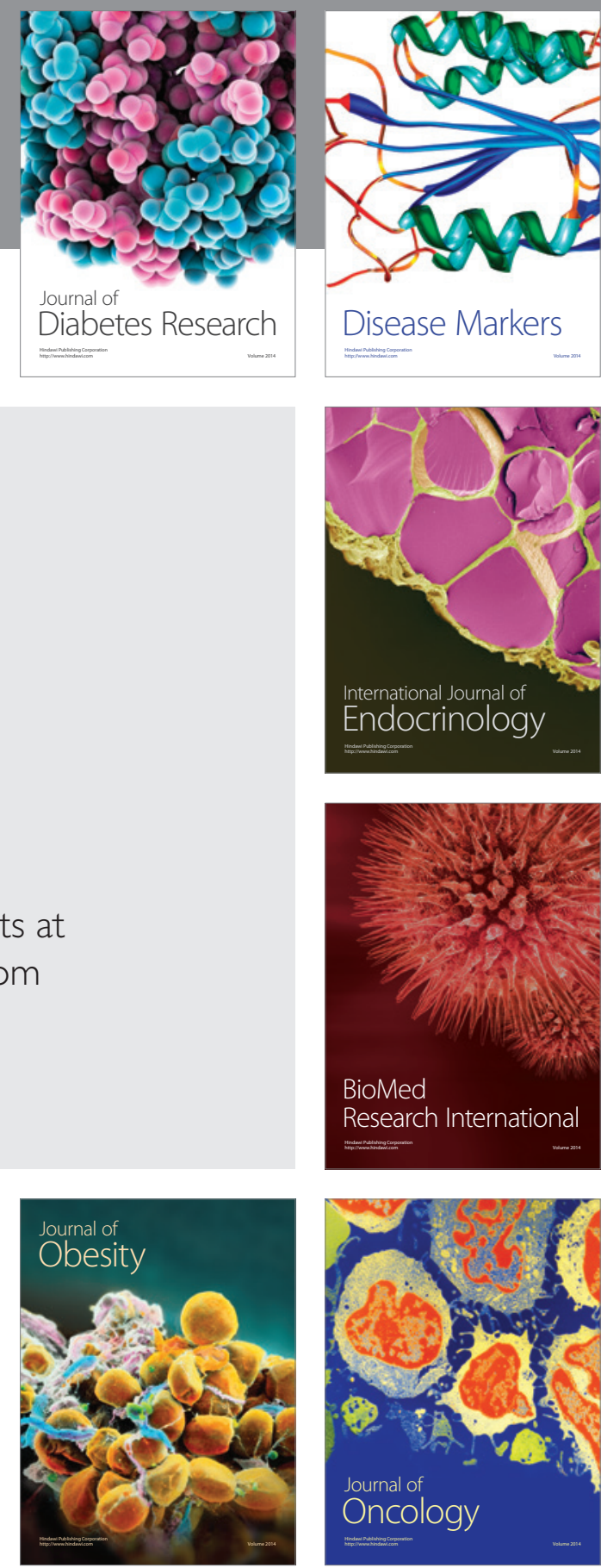

Disease Markers
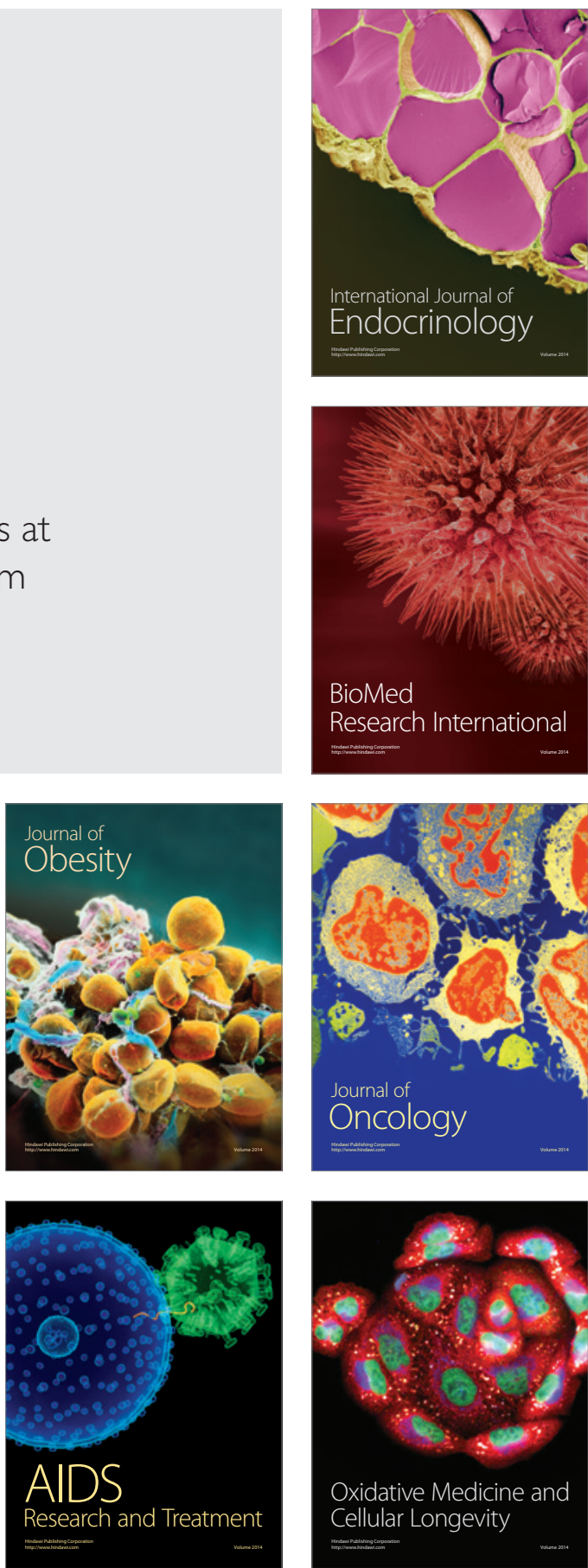